\title{
PROFIL GOOGLE SCHOLAR DOSEN UIN SYARIF HIDAYATULLAH JAKARTA BERBASIS WEBOMETRICS
}

\author{
Azkia Muharom Albantani \\ e-mail: azki@uinjkt.ac.id \\ Universitas Islam Negeri (UIN) Syarif Hidayatullah Jakarta
}

Jalan Ir. Haji Juanda No.95 Ciputat, Tangerang Selatan

\begin{abstract}
Abstrak: Penelitian ini dilakukan dengan tujuan mendapatkan gambaran tentang profil dosen berbasis webometrics; mendapatkan gambaran tentang fasilitas UIN Jakarta berbasis webometrics; dan mendapatkan gambaran tentang profil dosen dalam Google Scholar. Metode yang digunakan dalam penelitian ini adalah metode survei, terutama dalam menjaring responden sebagai sumber data. Dalam penyajian data, penelitian ini menggunakan metode deskriptif analisis, yaitu menggambarkan hasil penelitian yang diperoleh dari survei mengenai Profil Dosen FITK berbasis Google Scholar. Penelitian dilakukan dalam kurun waktu 6 bulan (1 April - 31 September 2015). Daftar Urut Kepangkatan (DUK) menunjukkan bahwa jumlah dosen tetap PNS FITK UIN Jakarta sebanyak 163 orang. Namun setelah dilakukan studi pelacakan, hanya 35 dosen yang baru memiliki profil dalam Google Scholar. Dari 35 dosen tersebut, baru 19 orang yang memiliki nilai dalam kutipan, h-index, dan h10-index. Prof. Dr. Abuddin Nata, MA merupakan dosen terproduktif dan paling banyak dikutip versi Google Scholar di lingkungan FITK UIN Jakarta. Karya-karya ilmiahnya sudah dikutip 1600-an kali di dalam karya ilmiah lain. Beliau juga memiliki nilai h-index tertinggi yaitu 17 (tujuh belas) dan nilai i10-index tertinggi yaitu 21 (dua puluh satu).
\end{abstract}

Kata-kata Kunci: profil dosen, google scholar, webometrics

\section{GOOGLE SCHOLAR PROFILE OF LECTURERS BASED ON WEBOMETRICS AT UIN SYARIF HIDAYATULLAH JAKARTA}

\begin{abstract}
This research aims to obtain an overview of the profiles of lecturers based on webometrics, a general description of webometrics-based facilities at UIN Jakarta, and the profiles of the lecturers on Google Scholar. The method used in this study is a survey method, especially in taking the respondents as a data source. In presenting the data, this study uses descriptive analysis method which illustrates the results obtained from the survey of the profiles of FITK (Faculty of Education and Teachers Training) lecturers on Google Scholar. The study was conducted within a period of 6 months (April 1st to September 31st, 2015). List of Ranks shows the number of permanent lecturers (civil servants) of FITK UIN Jakarta is 163 lecturers. Nevertheless, after conducting a tracking study, there are 35 lecturers only who already have a profile account on Google Scholar. Out of 35 lecturers, only 19 lecturers have values in citations, $h$-index, and h10-index. Prof. Dr. Abuddin Nata, M.A. is the most prolific and most widely cited lecturer on Google Scholar in the Faculty of Education and Teachers Training (FITK) of UIN Jakarta. His scientific works have been cited 1600 times in other works. He has also the highest h-index value, 17 (seventeen), and the highest i10-index, 21 (twenty one).
\end{abstract}

Keywords: profile of lecturer, google scholar, webometrics

\section{PENDAHULUAN}

Reformasi pendidikan yang diawali dengan kebijakan otonomisasi pada satuan pendidikan, dan berujung pada perluasan kewenangan guru dalam mengembangkan pembelajaran yang digerakkan sejak akhir abad ke-20 telah berpenetrasi pada semua aspek pendidikan, bahkan PP No. 19 tahun 2005, tentang Standar Nasional Pendidikan (SNP), mengamanahkan untuk dilakukan standarisasi delapan aspek pendidikan, yakni isi kurikulum, rumusan kompetensi lulusan, pendidikan tan tenaga kependidikan, proses pembelajaran, sarana dan prasarana pendidikan, pembiayaan, penilaian, dan pengelolaan.

Proses pendidikan terus berkembangan seiring dengan perkembangan zaman kehidupan manusia, terutama berkaitan dengan perkembangan teknologi. 
Perkembangannya yang sangat pesat mengubah hampir semua hal dalam proses pendidikan. Banyak sekali hal positif dari perkembangan teknologi untuk menghasilkan pendidikan yang efisien dan efektif. Tuntutan global menuntut dunia pendidikan untuk selalu senantiasa menyesuaikan perkembangan teknologi terhadap usaha dalam meningkatkan mutu pendidikan, terutama penyesuaian penggunaan Teknologi Informasi dan Komunikasi bagi dunia pendidikan (Rusman, 2012).

Meningkatnya kebutuhan akan informasi mendorong manusia untuk mengembangkan teknologi-teknologi baru agar pengolahan data dan informasi dapat dilakukan dengan mudah dan cepat. Salah satu teknologi yang sedang berkembang dengan pesat saat ini adalah teknologi informasi/komputer dan teknologi internet. Dengan adanya internet akan mempermudah dan mempercepat proses pengolahan data, mencari informasi dan lain-lain.

Universitas sebagai jenjang pendidikan tertinggi juga dituntut meningkatkan kualitas proses pendidikan dengan melalui ranking webometrics. Hal ini tentu merupakan pekerjaan rumah yang sangat besar bagi para tenaga pendidik dan tenaga kependidikan dalam rangka meningkatkan proses pendidikan berbasis teknologi informasi dan komunikasi.

Dari tahun ke tahun, ranking Webometrics UIN Jakarta selalu mengalami peningkatan. Dilansir dari situs http:/ / www.webometrics.info yang mereview ribuan situs-situs universitas di dunia tersebut, pada Januari 2015 UIN Jakarta menempati ranking 1 dari seluruh PTKIN di Indonesia, ranking 20 dari seluruh universitas yang ada di Indonesia, dan ranking 2294 universitas dunia (Redaksi UIN News, 2015).

Dosen sebagai peneliti merupakan orang yang melakukan aktivitas dengan menggunakan metode ilmiah dalam memperoleh pengetahuan. Peneliti dalam hal ini juga termasuk dalam hal membimbing mahasiswa untuk membuat karya ilmiah seperti Tugas Akhir, Skripsi, Tesis, Disertasi maupun jurnal ilmiah. Kualitas dosen sebagai peneliti dilihat dari kualitas karya tulis ilmiah yang dihasilkan. Untuk menghasilkan karya ilmiah yang berkualitas dibutuhkan sumber-sumber yang valid dan up to date.

Salah satu cara untuk mendapatkan sumbersumber ilmiah yang up to date adalah dengan menelusuri situs-situs yang menyediakan tulisan ilmiah dan bersertifikasi. Pada media online, informasi perkembangan ilmu pengetahuan terbaru terjadi dengan sangat cepat. Di sisi lain, situs online digunakan oleh dosen untuk menyebarkan informasi hasil penelitian mereka. Jadi, di situs tersebut terjadi proses: ada yang menambah koleksi karya ilmiah dan ada yang mengambil/memanfaatkan karya ilmiah tersebut.

Situs karya ilmiah ada yang berfungsi sebagai pintu gerbang atau ada yang merupakan rumah dari karya ilmiah tersebut. Situs yang berfungsi sebagai pintu gerbang hanya menunjukkan jalan menuju rumah karya ilmiah, sedangkan situs karya ilmiah menampung tulisan ilmiah. Beberapa contoh situs yang berfungsi sebagai pintu gerbang atau directory adalah Google Scholar atau Google Cendekia, DOAJ (Directory of Open Access Journals), dan Garuda Dikti.

Seluruh dosen tetap UIN Jakarta sudah difasilitasi email dengan domain uinjkt. Namun, kenyataannya di lapangan masih banyak dosen yang lebih memilih menggunakan email tanpa afiliasi dengan alasan privasi dan sudah sejak lama digunakan. E-mail dengan domain uinjkt bekerjasama dengan perusahaan google yang menyediakan fasilitas Google Cendekia. Fasilitas tersebut memudahkan pemilik akun untuk mengetahui berapa banyaknya sitasi yang dilakukan untuk seluruh karya ilmiah yang dimilikinya. Fasilitas tersebut juga merupakan salah satu penilaian yang digunakan untuk memberikan peringkat webometric perguruan tinggi.

Pada tahun 1997 ditemukan sebuah metode metric baru dan diberi nama dengan webometrics. Metode ini dideskripsikan sebagai sebuah studi tentang seluruh komunikasi berbasis jaringan komputer (termasuk world wide web) dengan menggunakan metode informetrics. Informetrics adalah studi tentang aspek-aspek kuantitatif dari informasi. Ini termasuk produksi, publikasi dan penggunaan semua bentuk informasi, terlepas dari bentuk atau asal. Dengan demikian, informetrics meliputi bidang: (1) Scientometrics, yang mempelajari aspek kuantitatif ilmu; (2) Webometrics, yang mempelajari aspek-aspek kuantitatif dari World Wide Web; (3) Cybermetrics, yang mirip dengan webometrics, namun memperluas definisi yang mencakup sumber daya elektronik; (4) Bibliometrics, yang mempelajari aspek kuantitatif dari informasi yang dicatat.

Ada konsep yang berbeda dari informetrics, bibliometrics dan scientometrics. Bidang informetrics mencakup bidang bibliometrics dan scientometrics yang definisinya diadopsi secara luas oleh beberapa peneliti (Brookes, 1990, Egghe and Rousseau, 1990, TagueSutcliffe, 1992). Informetrics didefinisikan sebagai studi tentang aspek-aspek kuantitatif dari informasi dalam bentuk apapun. Bibliometrics didefinisikan 
sebagai studi tentang aspek-aspek kuantitatif dari penyebaran, produksi dan penggunaan informasi yang dicatat, sedangkan scientometrics sebagai studi tentang aspek-aspek kuantitatif dari ilmu (Jati, 2013).

Webometrics adalah sebuah sistem perangkingan dunia yang berbasis web. Peringkat ini diperbaharui dua kali dalam setahun (Januari dan Juli). Tujuan utama dari perangkingan ini adalah (1) Mendorong implementasi teknologi informasi dan komunikasi, khususnya kehadiran Perguruan Tinggi dalam komunitas WEB, dan (2) yang paling utama adalah memotivasi Perguruan Tinggi untuk mempublikasikan karya-karya ilmiahnya ke masyarakat dunia.

Google Cendekia (Google Scholar) merupakan layanan yang memungkinkan pengguna malakukan pencarian materi-materi akademik berupa teks dalam berbagai format publikasi. Diluncurkan pada tahun 2004, indeks Google Cendekia mencakup jurnaljurnal online dari publikasi ilmiah. Google Cendekia menyediakan sarana yang mudah untuk mencari literatur akademis secara luas. Seseorang dapat mencari karya ilmiah di seluruh bidang ilmu dan referensi dari satu tempat: makalah peer-reviewed, tesis, disertasi, buku, abstrak, dan artikel, yang berasal dari penerbit akademis, komunitas profesional, universitas, dan organisasi akademis lainnya. Google Cendekia sangat membantu seseorang dalam mengidentifikasi penelitian yang paling relevan dari seluruh penelitian akademis. Google Cendekia bertujuan menyusun artikel seperti yang dilakukan peneliti, dengan memperhatikan kelengkapan teks setiap artikel, penulis, publikasi yang menampilkan artikel, dan frekuensi penggunaan kutipan artikel dalam literatur akademis lainnya. Hasil paling relevan akan selalu muncul pada halaman pertama (Susrini, 2009).

Google Cendekia adalah layanan pencarian materi - materi pelajaran berupa teks dalam berbagai format publikasi seperti doc dan pdf. Indeks Google Cendekia menyediakan cara yang mudah untuk mencari literatur akademis berupa jurnal - jurnal ilmiah, makalah peer-reviewed, thesis, buku, abstrak dan artikel dari penerbit akademis, komunitas profesional, pusat data pracetak, serta universitas dengan informasi yang relevan. Sumber informasi pada Google Cendekia lebih akurat dibanding dengan penggunaan search engine google yang harus menghubungkan terlebih dahulu ke situs situs dengan sumber informasi yang kurang relevan. Saat ini Google Cendekia memiliki database yang mencapai jumlah ribuan record sudah lebih dari cukup untuk dapat menemukan berbagai informasi mengenai tulisan ilmiah, laporan penelitian, artikel, dan jurnal-jurnal ilmiah.

Profil di Google Cendekia berisi daftar semua tulisan seorang penulis (buku, makalah, artikel, dan sebagainya) yang dikutip (cited) oleh penulis lain. Tulisan karya penulis tersebut diacu sebagai referensi yang disebutkan di dalam daftar pustaka (bibliometrik). Daftar semua kutipan tersebut berasal dari search scholar yang secara otomatis ditemukan oleh Google apabila artikel/makalah terkait bisa ditemukan oleh Google.

Di dalam Google Cendekia terdapat dua istilah populer, yaitu h-index dan h10-index. H-index adalah seorang ilmuwan memiliki indeks-h jika ia memiliki paper sebanyak $\mathrm{h}$ dengan jumlah kutipan untuk setiap paper tersebut minimal sama dengan $h$. Sedangkan yang dimaksud dengan i10-index adalah seorang ilmuwan memiliki indeks-i10 jika masingmasing paper yang dimiliki telah dikutip minimal dalam 10 artikel berbeda (Chandraleka, 2015).

Saat ini, penggunaan Google Cendekia sudah merambah ke dalam kegiatan akademis perkuliahan. Contohnya berbagai karya tulis ilmiah dosen UIN Syarif Hidayatullah Jakarta, meliputi materi kuliah, laporan penelitian, artikel jurnal, dan sebagainya dapat diunggah melalui repository institusi dan selanjutnya akan terindeks oleh Google Cendekia.

Tabel 1 berikut profil publik google cendikia 12 Dosen UIN Jakarta yang diambil secara random oleh penulis melalui situs http:/ / scholar.google.co.id per tanggal 22 April 2015.

Tabel 1. Profil Google Cendekia Dosen UIN Jakarta

\begin{tabular}{|c|c|c|c|c|}
\hline No & Nama Dosen & $\begin{array}{l}\text { Jumlah } \\
\text { Kutipan }\end{array}$ & h-index & i10-index \\
\hline 1 & Azyumardi Azra & 2201 & 23 & 43 \\
\hline 2 & Saiful Mujani & 482 & 11 & 12 \\
\hline 3 & Jaenal Aripin & 314 & 9 & 9 \\
\hline 4 & Arskal Salim & 274 & 9 & 9 \\
\hline 5 & Oman Fathurahman & 153 & 7 & 7 \\
\hline 6 & $\begin{array}{l}\text { Muhbib Abdul } \\
\text { Wahab }\end{array}$ & 189 & 3 & 2 \\
\hline 7 & Ismiarni Komala & 77 & 6 & 4 \\
\hline 8 & Jejen Musfah & 48 & 2 & 2 \\
\hline 9 & Ismatu Ropi & 39 & 5 & 1 \\
\hline 10 & Ayang Utriza Yakin & 15 & 2 & 0 \\
\hline 11 & $\begin{array}{l}\text { Ahmad Sayuti } \\
\text { Anshari Nasution }\end{array}$ & 7 & 1 & 0 \\
\hline 12 & $\begin{array}{l}\text { Iwan Permana } \\
\text { Suwarna }\end{array}$ & 2 & 1 & 0 \\
\hline
\end{tabular}

Prof. Dr. Azyumardi Azra, MA menempati peringkat ke-8 (delapan) peneliti produktif se- 
Indonesia seperti dilansir oleh www.webometrics. info per Februari 2015. Namun jika dibandingkan dengan ilmuwan peringkat pertama sedunia seperti Sigmund Freud dengan jumlah kutipan 367305 dan h-index 251, peringkat beliau tersebut masih sangat tertinggal jauh. Dari 500 peringkat peneliti produktif se-Indonesia, hanya ada empat nama dosen UIN Jakarta yang menempati peringkat tersebut, yaitu Azyumardi Azra, Jaenal Aripin, Oman Fathurahman, dan Ismiarni Komala.

Banyak dosen yang menulis buku dan karya ilmiah lainnya, sangat disayangkan jika tidak diwadahi dengan fasilitas Google Cendekia yang telah disediakan oleh akun email uinjkt. Apabila seluruh dosen telah memilik profil Google Cendekia, semua karya ilmiah akan terpublikasi ke seluruh penjuru dunia. Kita pun akan mendapati kemudian tidak hanya satu nama saja dari dosen UIN Jakarta yang menempati peringkat sepuluh besar peneliti produktif se-Indonesia versi webometrics. Sebagai timbal balik untuk institusi, dapat mengantarkan UIN Jakarta menempati peringkat pertama Webometrics dari seluruh universitas di Indonesia, bahkan di Asia Tenggara. Berdasarkan pemikiran di atas, dipandang perlu untuk dilakukan penelitian tentang "Profil Google Scholar Dosen UIN Syarif Hidayatullah Jakarta berbasis Webometrics".

Webometrics sebagai tren dalam pengembangan dunia keilmuan di lingkungan universitas masih belum banyak dikenal oleh kalangan sivitas akademik sehingga menjadi pekerjaan rumah bagi pihak kampus untuk membuat istilah tersebut familiar. UIN Jakarta sebagai ikon universitas Islam harus dicarikan banyak solusi tentang pengembangan dan peningkatan peringkat webometrics dalam rangka memperluas eksistensi pendidikan yang bersifat professional Islami di kancah internasional. Selain itu, Sivitas akademika UIN Jakarta meliputi Dosen/ Pegawai/Mahasiswa belum seluruhnya memahami pentingnya peringkat webometrics bagi kemajuan ilmu di kampus. Berdasarkan berbagai hal tersebut, permasalahan yang akan dijawab melalui penelitian ini dapat dirumuskan sebagai berikut: Bagaimana Profil Dosen Tetap FITK UIN Jakarta dalam Google Scholar?

Penelitian ini bertujuan untuk mendapatkan gambaran tentang profil dosen berbasis webometrics. Selain itu, berbagai fasilitas UIN Jakarta berbasis webometrics perlu diungkap dalam rangka pengembangan dan peningkatan kualitas pengajaran, penelitian, dan pengabdian kepada masyarakat.
Secara khusus penelitian ini pun hendak mendapatkan gambaran tentang profil dosen dalam Google Scholar.

\section{METODE PENELITIAN}

Pendekatan yang digunakan dalam penelitian ini merupakan perpaduan jenis penelitian kuantitatif dan kualitatif. Metode yang digunakan dalam penelitian ini adalah metode survei, terutama dalam menjaring responden sebagai sumber data. Penelitian dilakukan dalam kurun waktu 6 bulan (1 April - 31 September 2015) bertempat di Fakultas Ilmu Tarbiyah dan Keguruan (FITK) Universitas Islam Negeri (UIN) Syarif Hidayatullah Jakarta.

Sumber data penelitian ini yaitu sumber bibliografis berupa sejumlah daftar pustaka (literatur, buku-buku, dan jurnal) yang terkait langsung dengan tema penelitian ini, dan data lapangan yang diperoleh melalui data dari Pustipanda (Pusat Teknologi Informasi dan Pangkalan Data) UIN Jakarta dan seluruh dosen FITK UIN Jakarta. Sumber primer data penelitian ini adalah hasil observasi dan kunjungan. Sedangkan sumber sekunder data penelitian ini adalah hasil pengamatan dan hasil pembacaan terhadap sejumlah literatur kepustakaan yang relevan dengan tema penelitian.

Sumber data primer diperlakukan sebagai fokus analisis data dan sebagai dasar dalam penarikan kesimpulan. Sedangkan sumber data sekunder digunakan sebagai pelengkap dan pemerkaya analisis data. Kedua sumber data dibaca secara terpadu (integratif).

Populasi dalam penelitian ini adalah seluruh dosen tetap UIN Syarif Hidayatullah Jakarta, sedangkan sampel yang diambil dalam penelitian ini adalah seluruh dosen tetap PNS Fakultas Ilmu Tarbiyah dan Keguruan UIN Jakarta. Pengambilan sampel yang digunakan adalah teknik pengambilan sampel secara purposive (purposive sampling), dalam arti: memilih responden yang telah jelas diketahui keberadaannya dan jumlahnya yang terjangkau.

Untuk mengambil data dan informasi mengenai "Profil Google Scholar Dosen UIN Syarif Hidayatullah Jakarta berbasis Webometrics", peneliti melakukan observasi dan kunjungan untuk mendapatkan data serta dokumentasi dari Pustipanda dan Google Cendekia. Selain itu, data penelitian ini dikumpulkan melalui studi teks (literatur) yang berkaitan dengan masalah penelitian. Data ini diolah melalui proses pembacaan ulang, pemahaman (verstehen), kategorisasi, klasifikasi (topik, tema, wacana, 
situasi), dan sistematisasi substansi pemikirannya. Dalam penyajian dan analisa data, penelitian ini menggunakan metode deskriptif analisis, yaitu menggambarkan hasil penelitian yang diperoleh dari survey mengenai Profil Dosen FITK berbasis Google Cendekia.

\section{HASIL DAN PEMBAHASAN}

Pemeringkatan Webometrics dimaksudkan untuk mengukur komitmen kampus dalam mempublikasikan karya ilmiah mereka di internet (online). Ada empat indikator utama yang digunakan webometrics, yaitu Presence (20 persen), Impact (50 persen), Openness (15 persen) dan Excellence (15 persen). Presence menunjukkan jumlah halaman website (html) dan halaman dinamik yang tertangkap oleh mesin pencari (Google), tidak termasuk rich files. Impact menunjukkan jumlah eksternal link yang unik (backlink) yang diterima oleh domain web universitas (inlinks) terindeks di mesin pencari yang tertangkap di Majestic SEO dan Ahref. Openness merupakan jumlah file dokumen (Adobe Acrobat (.pdf), Adobe PostScript (.ps, .eps), Microsoft Word (.doc,.docx) dan Microsoft Powerpoint (.ppt, .pptx) yang online/open di bawah domain website universitas yang tertangkap oleh mesin pencari (Google Scholar). Sedangkan parameter Excellence menunjukkan jumlah artikel ilmiah, publikasi dan sitasi perguruan tinggi di jurnal internasional yang terindeks di Schimago Institution Rangking dan Google Scholar (LPM UIN Jakarta, 2015).

Dari penilaian di atas dapat dilihat persentase penilaian yang tertinggi adalah dari Visibilitas (banyaknya backlink) jadi dapat dikatakan universitas yang memiliki ranking Webometrics yang bagus tentu akan bagus juga dalam penerapan Teknologi Komputer. Berbicara tentang World Class University (WCU), banyak indikator persyaratan universitas dapat menjadi WCU, yang terpenting adalah Reputasi universitas tersebut, yang terpenting harus kuat di berbagai elemen. Salah satunya adalah kualitas penelitian yang baik inovatif dan memiliki tema yang sangat spesifik, hasil penelitian tersebut kemudian dipublikasi secara intensif melalui jurnal internasional, sehingga hasilnya akan disitasi oleh peneliti lainnya untuk mendukung pengembangan penelitian lain yang mungkin mempunyai kesamaan tema. Selain itu, universitas harus terus memacu pengembangan pengetahuan dari tenaga pengajar, dan juga mengembangkan secara serius art center, cultur, scientifical, dan life society.

Secara umum, kualitas universitas dapat dikatakan baik jika dapat memenuhi beberapa kriteria yaitu di antaranya: kualitas penelitian, daya serap lulusan, mobilitas dosen/ mahasiswa yang international yang masuk dan keluar di perguruan tinggi tersebut untuk memberikan ceramah atau pertukaran dosen dan mahasiswa. Riwayat peringkat nasional Webometrics UIN Jakarta: (1) 2011 peringkat 60, (2) 2012 peringkat 59, (3) 2013 peringkat 41, (4) 2014 peringkat 34, dan (5) 2015 peringkat 20 (Pustipanda UIN Jakarta, 2015).

\section{Fasilitas Penunjang Webometrics}

UIN Jakarta telah menyediakan berbagai macam fasilitas berbasis TIK untuk meningkatkan mutu pendidikan. Adapun fasilitas untuk Tenaga Pendidik, Tenaga Kependidikan, dan Peserta Didik sebagai berikut.

\section{Academic Information System (AIS)}

Sistem Informasi Akademik (AIS) UIN Jakarta merupakan fasilitas yang diberikan kampus kepada sivitas akademikanya untuk dapat memantau berbagai aktivitas administrasi akademik yang sedang berlangsung. Sistem ini dilengkapi dengan keamanan akun yang harus dimiliki tiap penggunanya. Terdapat tiga akun dalam sistem ini, yaitu akun pengelola administrasi, akun dosen, dan akun mahasiswa. Alamat https:/ / ais.uinjkt.ac.id

2. Sistem SPMB Online

UIN Jakarta sejak 2009 telah menggunakan Sistem SPMB berbasis online. Hal ini memudahkan masyarakat untuk mengakses sistem tersebut kapan pun dan dimana pun. Sistem ini pun berbasis paperless dikarenakan semua berkas yang dibutuhkan harus berbentuk digital. Adapun SPMB yang telah diselenggarakan online di antaranya SPMB Mandiri S1, S2, dan S3, SPAN-PTKIN, serta SNMPTKIN. Alamat http://spmb.uinjkt.ac.id

3. Sistem Katalog Perpustakaan UIN, alamat http:// katalog.uinjkt.ac.id

4. Sistem Tracer Alumni (Beta Version - 2011)

Tracer Study Alumni juga sudah mulai dikembangkan versi online oleh pihak kampus. Hal tersebut diselenggarakan dengan menggunakan fasilitas google form dalam mempersiapkan angket online untuk alumni. Hal tersebut memudahkan alumni supaya dapat mengisi angket tersebut tanpa terhambat oleh jarak dan waktu. Alamat http:// alumni.uinjkt.ac.id

5. Helpdesk Pustipanda

Helpdesk merupakan fasilitas yang disediakan 
oleh UIN Jakarta untuk memberikan solusi terhadap problematika dalam penggunaan berbagai fasilitas teknologi informasi dan komunikasi yang dibutuhkan oleh sivitas akademika. Salah satu fasilitas dalam sistem ini adalah tersedianya berbagai macam formulir online untuk pendaftaran email uinjkt. Alamat http://helpdesk.uinjkt.ac.id

\section{Portal E-Journal}

Sesuai dengan amanat Kemenristekdikti (Dahulu Kemendikbud) bahwa pengelolaan jurnal ilmiah berkala harus segera dionlinekan, UIN Jakarta telah mempersiapkan fasilitas berupa portal jurnal ilmiah berkala berbasis online. Berbagai jurnal yang dimiliki seluruh fakultas tersedia di portal ini. Bahkan beberapa jurnal yang dimiliki UIN Jakarta telah terindeks Scopus dan DOAJ. Hal ini merupakan fasilitas yang sangat besar dalam meningkatkan peringkat Webometrics dalam hal kepemilikan h-indeks sivitas akademika. Selain itu, semakin banyak jurnal di UIN Jakarta terindeks berbagai portal indeksasi jurnal ilmiah berkala bertaraf nasional dan internasional, semakin besar pula kemungkinan bahwa karya-karya sivitas UIN Jakarta dapat dikenal dan dibaca dunia. Alamat http:/ /journal.uinjkt.ac.id

\section{E-Learning}

Saat ini, UIN Jakarta sedang mengembangkan pembelajaran berbasis online. Dengan berbekal email uinjkt hasil kerjasama pihak kampus dan google, para dosen diminta menggunakan fasilitas google classroom dalam pembelajaran sehari-hari. Oman Fathurahman merupakan salah satu dosen yang memiliki andil besar dalam pengembangan model pembelajaran online tersebut. Berbekal pengalamannya menggunakan google classroom dalam perkuliahan di Fakultas Adab dan Humaniora, beliau selalu diundang oleh fakultas-fakultas di lingkungan UIN dalam rangka sosialisasi penggunaan fasilitas tersebut. Penggunaan fasilitas tersebut akan berbuah optimal jika dikombinasikan dengan penggunaan sistem AIS.

\section{Insitutional Repository}

Institusional Repository merupakan fasilitas wajib yang dimiliki tiap institusi pendidikan tinggi, begitupula UIN Jakarta. Fasilitas ini merupakan wadah publikasi seluruh karya-karya ilmiah yang disusun oleh sivitas akademika UIN Jakarta. Skripsi, Tesis, Disertasi, Laporan Penelitian, dan jenis lainnya dapat ditemukan di dalam fasilitas tersebut. Alamat http://repository.uinjkt.ac.id

9. Sistem Laporan Kinerja Pegawai (e-LKP)
Seluruh pegawai diwajibkan melaporkan seluruh tugas yang telah dilakukan ke dalam sistem laporan kinerja pegawai online. Sistem ini memiliki kelebihan untuk memantau kinerja seluruh pegawai di lingkungan UIN Jakarta. Hasil penilaian dari sistem ini pun sangat berpengaruh kepada nilai remunerasi yang akan diperoleh pegawai. Semakin baik nilai hasil laporannya, semakin stabil juga nilai remunerasi untuknya. Alamat http://lkp.uinjkt.ac.id 10. E-mail Dosen/Pegawai/Lembaga

Tren surat menyurat digital sudah berkembang sejak lama, salah satunya melalui e-mail. UIN Jakarta pun tak mau ketinggalan memberikan fasilitas tersebut kepada seluruh warganya. Kerjasama pihak kampus dan pihak google memberikan fasilitas e-mail @uinjkt.ac.id merupakan sebuah kebanggaan yang sangat baik. Terlebih lagi fasilitas email tersebut memberikan nilai tambah dengan dilengkapi fasilitas komputasi awan google drive yang dapat menyimpan data sampai dengan 10 Terabyte.

11. Blog Dosen dengan domain nama.

Blog dosen merupakan nilai tambah dari kepemilikan e-mail @uinjkt.ac.id. Setiap dosen yang memiliki e-mail tersebut dapat memanfaatkan fasilitas google site untuk membuat blog dosen. Blog yang sudah dibuat akan mendapatkan domain lec.uinjkt.ac.id setelah didaftarkan melalui fasilitas helpdesk. Adapun manfaat dari penggunaan blog tersebut di antaranya (1) sebagai curriculum vitae online dosen bersangkutan, (2) sebagai wadah publikasi karya ilmiah yang pernah dibuat, dan (3) sebagai wadah untuk berbagi materi perkuliahan kepada mahasiswa.

\section{E-mail Mahasiswa}

Fasilitas e-mail mahasiswa tidak berbeda jauh dengan e-mail dosen. Hal yang membedakan hanyalah dari segi penamaan email tersebut. Jika dosen menggunakan email @uinjkt.ac.id, maka mahasiswa menggunakan email @mhs.uinjkt.ac.id. sejak penerimaan mahasiswa baru tahun akademik 2014/2015, seluruh mahasiswa baru secara langsung mendapatkan email tersebut. Alamat email tersedia di AIS dan dapat diakses menggunakan NIM sebagai password log in.

13. Blog Mahasiswa dengan domain nama.mhs.uinjkt. ac.id

Fasilitas blog mahasiswa tidak berbeda jauh dengan blog dosen. Hal yang membedakan pun hanyalah dari segi penamaan blog tersebut. Mahasiswa akan mendapatkan blog dengan domain mhs.uinjkt.ac.id. Pihak kampus selalu mengadakan 
perlombaan dalam desain grafis blog tingkat universitas.

\section{Website}

Sebagai wadah publikasi berbagai kegiatan, seluruh unit baik yang besar maupun yang kecil di lingkungan kampus secara keseluruhan difasilitasi oleh website dengan domain uinjkt.ac.id (Pustipanda UIN Jakarta, 2015).

\section{Profil Dosen FITK UIN Jakarta}

Tabel 2-4 berikut adalah data mengenai tenaga pendidik FITK UIN Syarif Hidayatullah Jakarta.

Tabel 2. Dosen Tetap Menurut Jenis Kelamin

\begin{tabular}{ccc}
\hline Laki-laki & Perempuan & Jumlah \\
\hline 94 & 79 & 173 \\
\hline
\end{tabular}

Tabel 3. Dosen Tetap Menurut Status Pekerjaan

\begin{tabular}{ccc}
\hline PNS & Tetap Kontrak & Jumlah \\
\hline 163 & 10 & 173 \\
\hline
\end{tabular}

Tabel 4. Dosen Tetap Menurut Jenjang Pendidikan

\begin{tabular}{cccc}
\hline Strata I & Strata II & Strata III & Jumlah \\
\hline 15 & 115 & 43 & 173 \\
\hline
\end{tabular}

Pemeringkatan Dosen FITK versi Google Scholar

Google Scholar menyajikan jumlah paper dan citation untuk tiap domain akademik. Hasil dari pangkalan data Scholar menunjukkan papers, reports, dan elemen akademik yang lain. Pihak universitas perlu melanggan lebih banyak publikasi internasional dan menjadi anggota dari masyarakat profesi sehingga dosen dapat mengirimkan hasil penelitiannya ke badan publikasi internasional tersebut. Hal ini akan meningkatkan jumlah publikasi yang diindeks oleh Google Scholar. Upaya peningkatan rangking pada kriteria Scholar juga dapat diamati dengan banyaknya karya ilmiah yang dapat dikenal dan diindeks oleh Scopus.

Scopus adalah database abstrak dan sitasi terbesar dari dari berbagai sumber web literatur dan kualitas riset di seluruh dunia. Scopus dirancang secara khusus untuk memenuhi kebutuhan para intelektual dan masyrakat ilmiah dengan mudah, komprehensif, terkini dan cepat melalui penyediaan fasilitas pencarian online interaktif yang handal. Tabel 5 berikut menunjukkan peringkat dosen FITK versi Google Scholar (data diambil pada tanggal 12 Nopember 2015)

Tabel 5. Profil Google Cendekia Dosen FITK UIN Jakarta

\begin{tabular}{|c|c|c|c|c|c|}
\hline No & Nama & NIP & KUTIPAN & H-INDEX & H10-INDEX \\
\hline 1 & Prof. Dr. Abuddin Nata, MA & 195408021985031002 & 1642 & 17 & 21 \\
\hline 2 & Yudhi Munadi, MA & 197012031998031003 & 522 & 4 & 3 \\
\hline 3 & Prof.Dr. Dede Rosyada, MA & 195710051987031003 & 295 & 5 & 4 \\
\hline 4 & Dr. Muhbib, M.Ag & 196810231993031002 & 209 & 3 & 2 \\
\hline 5 & Dr. Jejen, MA & 197706022005011004 & 57 & 3 & 2 \\
\hline 6 & Dr. Yanti Herlanti, M.Pd & 197101192008012010 & 41 & 2 & 1 \\
\hline 7 & Wahdi, S.Ag, M.Ag & 197604222007011012 & 36 & 4 & 1 \\
\hline 8 & Didin Syafruddin, MA, Ph.D & 196003071990021001 & 32 & 3 & 1 \\
\hline 9 & Dr. Ahmad Sofyan, M.Pd & 196501151987031020 & 31 & 1 & 1 \\
\hline 10 & Salamah Agung, MA, Ph.D & 197906242006042002 & 28 & 1 & 1 \\
\hline 11 & Muhammad Zuhdi, M.Ed, Ph.D & 197207041997031002 & 26 & 3 & 1 \\
\hline 12 & Toto Edidarmmo, MA & 197602252008011020 & 24 & 2 & 1 \\
\hline 13 & Dr. Abd. Rozak, M.Si & 196909081996031004 & 22 & 4 & 0 \\
\hline 14 & Dr. Fauzan, MA & 197611072007011013 & 17 & 2 & 1 \\
\hline 15 & Bahrissalim, M.Ag & 196803071998031002 & 15 & 2 & 0 \\
\hline 16 & Prof. Dr. Ahmad Thib Raya, MA & 195504211982031007 & 14 & 1 & 1 \\
\hline 17 & Dr. A. Sayuti A. Nasution, MA & 195408282001121001 & 12 & 2 & 0 \\
\hline 18 & Maifalinda Fatra, M.Pd & 197005281996032002 & 11 & 2 & 0 \\
\hline 19 & Dwi Nanto, M.Si & 197903192009011009 & 9 & 2 & 0 \\
\hline 20 & Abdul Muin, M.Pd & 197512012006041003 & 7 & 2 & 0 \\
\hline 21 & Dr. Sururin, M.Ag. & 197103191998032001 & 6 & 1 & 0 \\
\hline 22 & Dr. Alek, M.Pd & 196909122009011008 & 4 & 1 & 0 \\
\hline 23 & Prof.Dr. H. Aziz Fahrurrozi, MA & 195206091981031004 & 1 & 1 & 0 \\
\hline 24 & Prof. Dr. H. Moh. Matsna, HS, MA & 195108071980031006 & 0 & 0 & 0 \\
\hline
\end{tabular}




\begin{tabular}{llcccc}
\hline No & \multicolumn{1}{c}{ Nama } & NIP & KUTIPAN & H-INDEX & H10-INDEX \\
\hline 25 & Dr. Kadir, M.Pd & 196708121994021001 & 0 & 0 & 0 \\
26 & Drs. H. Nurochim, MM & 195907151984031003 & 0 & 0 & 0 \\
27 & Dr. Fahriany, M.Pd & 197006111991012001 & 0 & 0 & 0 \\
28 & Ahmad Royani, M.Hum & 196904281997031001 & 0 & 0 & 0 \\
29 & N. Lalah Alawiyah,MA & 197103231998032009 & 0 & 0 & 0 \\
30 & Maswani, MA & 197305051999032003 & 0 & 0 & 0 \\
31 & Iwan Permana Suwarna, M.Pd & 197805042009011013 & 0 & 0 & 0 \\
32 & Makyun Subuki, M.Hum & 198003052009011015 & 0 & 0 & 0 \\
33 & Raswan, M.Pd & 198302072011011009 & 0 & 0 & 0 \\
34 & Rosida Erowati, M.Hum & 197710302008012009 & 0 & 0 & 0 \\
35 & Fathiah Alatas, M.Si & 198302152009122008 & 0 & 0 & 0 \\
36 & Anissa Windarti, M.Sc & 198208022011012005 & 0 & 0 & 0 \\
37 & Jakiatin Nisa, M.Pd & 198312052011012012 & 0 & 0 & 0 \\
38 & Teguh Khaerudin, M.App.Ling & 198110312011011006 & 0 & 0 & 0 \\
39 & Zaharil An'asy, M.Hum & 197610072007101002 & 0 & 0 & 0 \\
\hline
\end{tabular}

Dari tabel 5 dapat disimpulkan bahwa dari 23 dosen yang memiliki nilai h-index dalam Google Scholar di antaranya 6 dosen dari Jurusan Pendidikan Agama Islam (PAI), 5 dosen dari Jurusan Pendidikan Bahasa Arab (PBA), 4 dosen dari Jurusan Pendidikan IPA, 3 dosen dari Jurusan Pendidikan IPS, 2 dosen dari Jurusan Pendidikan MTK, 1 dosen dari Jurusan Pendidikan Bahasa Inggris, 1 dosen dari Program Studi Manajemen Pendidikan, dan 1 dosen dari Program Studi Pendidikan Guru MI.

Daftar Urut Kepangkatan (DUK) menunjukkan bahwa jumlah dosen tetap PNS FITK UIN Jakarta sebanyak 163 orang. Namun setelah dilakukan studi pelacakan, hanya 38 dosen yang baru memiliki profil dalam Google Scholar. Dari 38 dosen tersebut, baru 23 orang yang memiliki nilai dalam kutipan, h-index, dan h10-index.

Penulis meyakini bahwa 163 dosen FITK UIN Jakarta adalah dosen yang telah memiliki beberapa bahkan banyak karya tulis ilmiah dan telah dipublikasikan baik secara cetak maupun online. Namun sangat disayangkan apabila dosendosen tersebut belum memiliki profil publik Google Scholar. Profil tersebutlah yang akan mengakomodasi banyaknya kutipan yang diperoleh oleh karya tulis ilmiah dari dosen tersebut secara otomatis dengan konsep bibliometrik.

Pada saat ini, karya tulis seperti skripsi, tesis, dan disertasi sudah dipublikasikan oleh mayoritas perguruan tinggi di Indonesia khususnya UIN Syarif Hidayatullah Jakarta. Dalam penulisan tugas karya tulis tersebut, mahasiswa akan mengutip berbagai hasil pemikiran dosen-dosennya berupa buku dan artikel jurnal. Kutipan tersebut secara otomatis akan dicantumkan oleh mahasiswa ke dalam catatan kaki dan daftar pustaka. Setelah karya tersebut dionlinekan, Google Cendekia akan secara otomatis mengakumulasi berapa kali karya tulis ilmiah hasil pemikiran dosen tersebut dikutip. Setelah itu, akumulasi nilai tersebut dikonversi dalam nilai h-index dan i-10 index. Peneliti dan dosen yang memiliki nilai tinggi dalam h-index dan i-10 index akan berkesempatan besar masuk ke dalam peringkat tertinggi peneliti dan dosen berdedikasi dalam www. webometrics.info.

Prof. Dr. Abuddin Nata, MA., merupakan salah satu dosen terproduktif dan paling banyak dikutip versi Google Scholar. Karya-karya ilmiahnya sudah dikutip lebih dari 1600-an kali di dalam karya ilmiah lain. Adapun h-index tertinggi yaitu 17 (tujuh belas) juga dimiliki oleh Prof. Dr. Abuddin Nata, MA. Selain itu, h10-index tertinggi yaitu 21 (dua puluh satu) juga masih dipegang oleh Prof. Dr. Abuddin Nata, MA.

Belajar dari profil Prof. Dr. Abuddin Nata, MA., dosen-dosen seharusnya termotivasi untuk melahirkan banyak karya tulis ilmiah yang banyak konsumsi oleh masyarakat akademik. Para dosen harus terpacu untuk membuat karya tulis ilmiah yang berkualitas dan berpotensi banyak dikonsumsi oleh masyarakat akademik, seperti mahasiswa, dosen, wara institusi pendidikan, dan sebagainya.

Prof. Dr. Abuddin Nata, MA. menempati peringkat ketiga (ke-3) teratas versi google cendekia. Adapun dua dosen dengan posisi tepat di atasnya adalah Prof. Dr. M. Quraish Shihab dengan jumlah kutipan terhadap karyanya sebanyak 3000-an kali 
dan Prof. Dr. Azyumardi Azra dengan jumlah kutipan terhadap karyanya sebanyak 2000-an kali. Sebuah kebanggaan bagi Fakultas Ilmu Tarbiyah dan Keguruan UIN Jakarta memiliki dosen dengan prestasi yang sangat baik dalam bidang karya tulis ilmiah.

Selama ini pihak kampus selalu menggalakkan kegiatan-kegiatan dalam meningkatkan peringkat webometrics. Berbagai sosialisasi terkait penggunaan email dan blog berafiliasi UIN Jakarta serta kepemilikan profil Google Scholar sudah diselenggarakan beberapa kali di semua fakultas lingkungan UIN Jakarta.

Namun sayangnya, hasil optimal belum didapatkan oleh FITK UIN Jakarta sebagaimana data tabel di atas. Penulis berpendapat bahwa masih banyak dosen yang menganggap penggunaan email, blog, dan Google Scholar tidaklah penting. Selain itu, penulis beranggapan bahwa karya-karya ilmiah dosen FITK masih banyak yang belum dipublikasikan secara online sehingga belum terindeks oleh Google Scholar. Perlu diketahui bahwa UIN Jakarta memiliki sarana publikasi karya ilmiah sivitas akademikanya yang dinamakan repository. Dosen, Mahasiswa, dan Pegawai juga dapat membuat akun repositori personal untuk memudahkan upload data secara individu.

Pendekatan reward and punishment akan memberikan hasil optimal dalam mewajibkan seluruh dosen dalam menggunakan email, blog, dan Google Scholar. Kegiatan-kegiatan yang bersifat sosialisasi masih kurang diminati oleh dosen. Namun jika terdapat apresiasi bagi pemeroleh nilai h-indeks, maka dosen akan berlomba-lomba dalam meningkatkan h-indeks Google Scholar yang mereka miliki.

Selain itu, hasil penelusuran menunjukkan bahwa banyak karya ilmiah dosen telah dipublikasikan secara online. Karya tersebut pun telah dikutip banyak karya lain menurut penelusuran Google Scholar. Hal yang sangat disayangkan adalah dosen yang karyanya dikutip belum memiliki profil dalam Google Scholar sehingga mengakibatkan tidak terdeteksinya banyak kutipan, h-index, dan i10-index yang diperoleh dosen tersebut.

Penulis meyakini betapa sulitnya menumbuhkan kesadaran dalam diri seluruh warga akademik di lingkungan UIN Syarif Hidayatullah untuk samasama meningkatkan peringkat Webometrics kampus. Hal tersebut bertujuan untuk lebih mengenalkan kampus tercinta ke dunia luar di belahan Asia, Eropa, Amerika, dan Juga Timur Tengah.
Adapun kepemilikan blog dengan subdomain uinjkt.ac.id seharusnya menjadi kebanggaan dosen untuk mempublikasikan secara umum tentang berbagai riwayatnya di bidang pendidikan, organisasi, dan penulisan karya ilmiah. Selain itu, kepemilikan blog dapat dimanfaatkan oleh dosen untuk berbagi ide dan tulisan ringan kepada masyarakat luas melalui internet. Kabar gembiranya adalah tulisan ringan yang bagikan melalui blog tersebut akan terindeks oleh google cendekia apabila tulisan tersebut dikutip oleh seseorang dalam sebuah karya tulisnya. Dari 163 dosen tetap FITK UIN Jakarta, hanya 25 dosen yang telah memiliki blog berafiliasi kampus. Tabel 6 berikut adalah data kepemilikan blog dosen yang berhasil penulis dapatkan melalui helpdesk.uinjkt.ac.id (Oktober 2015).

Tabel 6. Data Blog Dosen UIN Jakarta

\begin{tabular}{cll}
\hline No & \multicolumn{1}{c}{ Nama Dosen } & \multicolumn{1}{c}{ Alamat Blog } \\
\hline 1 & Abdul Muin & http://abdulmuin.lec.uinjkt.ac.id \\
2 & Abdul Rozak & http://abdulrozak.lec.uinjkt.ac.id \\
3 & Abuddin Nata & http://abuddin.lec.uinjkt.ac.id \\
4 & Alek & http://alek.lec.uinjkt.ac.id \\
5 & Andri Noor & http://andrinoor.lec.uinjkt.ac.id \\
& Ardiansyah & \\
6 & Bahrissalim & http:// bahrissalim.lec.uinjkt.ac.id \\
7 & Burhanudin Milama & http:// burhanudinmilama.lec. \\
& & uinjkt.ac.id \\
8 & Dina Rahma Fadlilah & http://dinarahma.lec.uinjkt.ac.id \\
9 & E vi Sa pi n a t u l & http://evisapinatul.lec.uinjkt.ac.id \\
& Bahriah & \\
10 & Fauzan & http://fauzan.lec.uinjkt.ac.id \\
11 & Gusni Satriawati & http://gusnisatriawati.lec.uinjkt. \\
& & ac.id \\
12 & Lu'Luil Maknun & http://luluilmaknun.lec.uinjkt.ac.id \\
13 & Moria Fatma & http://moriafatma.lec.uinjkt.ac.id \\
14 & Muhammad Zuhdi & http://zuhdi.lec.uinjkt.ac.id \\
15 & N. Lalah Alawiyah & http://lalah.lec.uinjkt.ac.id/ \\
16 & Nanda Saridewi & http://nandasaridewi.lec.uinjkt. \\
& & ac.id \\
17 & Nida Husna & http://nidahusna.lec.uinjkt.ac.id \\
18 & Nuraida & http://nuraida.lec.uinjkt.ac.id \\
19 & Raswan & http://raswan.lec.uinjkt.ac.id \\
20 & Salamah Agung & http://salamahagung.lec.uinjkt.ac.id \\
21 & Suwito & http://suwito.lec.uinjkt.ac.id \\
22 & Syaripulloh & http://syaripulloh.lec.uinjkt.ac.id \\
23 & Wati Susiawati & http://watisusiawati.lec.uinjkt.ac.id \\
24 & Yanti Herlanti & http://yantiherlanti.lec.uinjkt.ac.id \\
25 & Zulfiani & http://zulfiani.lec.uinjkt.ac.id \\
\hline & &
\end{tabular}

Dari 25 blog yang telah dimiliki oleh dosen FITK UIN Jakarta, 5 blog belum memiliki subdomain 
uinjkt.ac.id. Selain itu, sebagian besar blog yang telah dimiliki, belum didesain dan dikelola secara baik sehingga memiliki kesan belum layak publikasi.

Namun sayangnya, mengelola desain blog dengan sistem google site bukan merupakan hal yang mudah dipelajari. Dosen seharusnya memperoleh pelatihan intensif mengenai pengelolaan desain blog tersebut. Sebelumnya dosen hanya mendapatkan pelatihan untuk menambah konten blog dan mendaftarkan subdomain blog. Sedangkan terkait pengelolaan desainnya, dosen harus mencari informasi mandiri melalui search engine google dan juga bertanya-tanya dengan mahasiswa yang telah pakar dalam desain blog.

Selain itu, beberapa dosen pun sudah memiliki blog. Namun sayangnya, blog tersebut tidak memiliki subdomain uinjkt.ac.id. Meskipun blog tersebut banyak diakses oleh khalayak ramai, namun tidak akan berefek untuk penambahan nilai Webometrics kampus. Ada baiknya pihak kampus memberikan fasilitas dan sosialisasi tambahan berupa migrasi data dari blog non-afiliasi menuju blog dengan afiliasi uinjkt.ac.id. Sepanjang penulis ketahui, berbagai fasilitas terkait pengembangan teknologi informasi dan komunikasi dalam bidang pendidikan telah tersedia di UIN Syarif Hidayatullah Jakarta dengan melalui fasilitas yang disediakan oleh PUSTIPANDA dengan media helpdesk.uinjkt.a.id.

Beberapa dukungan dan hambatan yang terjadi diuraikan sebagai berikut. Pertama, dalam rangka memberikan kemudahan kepada sivitas akademik UIN Jakarta untuk mengelola data, Pusat Teknologi Informasi dan Pangkalan Data (Pustipanda) UIN Jakarta menjalin kerjasama dengan Google Indonesia untuk memperkenalkan layanan aplikasi pengelolaan data dan pengenalan sejumlah aplikasi lainnya yang terangkum dalam fitur Google Apps untuk kepentingan akademik.

Kedua, Rektor UIN Jakarta (Prof. Dr. Dede Rosyada, MA) sangat memberikan perhatian yang sangat besar dalam upaya peningkatan pemeringkatan Webometrics UIN Jakarta. Salah satunya dengan terbitnya surat edaran tentang partisipasi sivitas akademika dalam peningkatan Webometrics kampus. Selain itu, berbagai kegiatan sosialisasi terkait penggunaan fasilitas penunjang Webometrics selalu diselenggarakan secara rutin dan berkelanjutan di setiap fakultas. Salah satu yang terdekat adalah kegiatan pelatihan pengelolaan blog dosen dan pembuatan profil Google Scholar yang diselenggarakan oleh kerjasama pihak Pustipanda,
Pusat Perpustakaan, dan Lembaga Penjaminan Mutu UIN Jakarta.

Ketiga, mayoritas dosen berposisi sebagai imigran teknologi yang kurang familiar dengan penggunaan teknologi dalam berbagai kegiatan. Dengan adanya reward and punishment terhadap prestasi dosen dalam google cendekia dan desain blog terbaik, kemungkinan besar akan menggugah dosen untuk lebih akrab dengan teknologi.

Keempat, Sebagian besar dosen masih memandang bahwa berbagai aktivitas kampus harus menggunakan kertas. Padahal ketersediaan kertas bergantung pada ketersediaan pohon. Dengan penggunaan email secara rutin, penggunaan kertas dapat diminimalisir dalam rangka go green activities. Surat menyurat pun secara rutin digantikan dengan peran email yang sudah terintegrasi dengan ponsel cerdas (smartphone).

\section{PENUTUP}

\section{Kesimpulan}

Dari tahun ke tahun, ranking Webometrics UIN Jakarta selalu mengalami peningkatan. Dilansir dari situs http://www.webometrics.info yang mereview ribuan situs-situs universitas di dunia tersebut, pada Januari 2015 UIN Jakarta menempati ranking 1 dari seluruh PTKIN di Indonesia, ranking 20 dari seluruh universitas yang ada di Indonesia, dan ranking 2294 universitas dunia.

UIN Jakarta telah menyediakan berbagai macam fasilitas berbasis TIK untuk meningkatkan mutu pendidikan. Adapun fasilitas untuk Tenaga Pendidik, Tenaga Kependidikan, dan Peserta Didik di antaranya (1) Academic Information System (AIS), (2) Helpdesk Pustipanda, (3) Portal E-Journal, (4) Insitutional Repository, (5) E-mail Dosen/Pegawai/ Lembaga/Mahasiswa, (6) Blog Dosen/Mahasiswa, dan seterusnya.

Daftar Urut Kepangkatan (DUK) menunjukkan bahwa jumlah dosen tetap PNS FITK UIN Jakarta sebanyak 163 orang. Namun setelah dilakukan studi pelacakan, hanya 35 dosen yang baru memiliki profil dalam Google Cendekia. Dari 35 dosen tersebut, baru 19 orang yang memiliki nilai dalam kutipan, h-index, dan h10-index.

Prof. Dr. Abuddin Nata, MA meupakan dosen terproduktif dan paling banyak dikutip versi Google Cendekia di lingkungan FITK UIN Jakarta. Karyakarya ilmiahnya sudah dikutip 1600-an kali di dalam karya ilmiah lain. Beliau juga memiliki nilai h-index 
tertinggi yaitu 17 (tujuh belas) dan nilai i10-index tertinggi yaitu 21 (dua puluh satu).

Selama ini pihak kampus selalu menggalakkan kegiatan-kegiatan dalam meningkatkan peringkat webometrics. Berbagai sosialisasi terkait penggunaan email dan blog berafiliasi UIN Jakarta serta kepemilikan profil Google Cendekia sudah diselenggarakan beberapa kali di semua fakultas lingkungan UIN Jakarta.

Namun sayangnya, hasil optimal belum didapatkan oleh FITK UIN Jakarta sebagaimana data tabel di atas. Penulis berpendapat bahwa masih banyak dosen yang menganggap penggunaan email, blog, dan Google Cendekia tidaklah penting. Selain itu, penulis beranggapan bahwa karya-karya ilmiah dosen FITK masih banyak yang belum dipublikasikan secara online sehingga belum terindeks oleh Google Cendekia. Perlu diketahui bahwa UIN Jakarta memiliki sarana publikasi karya ilmiah sivitas akademikanya yang dinamakan repository. Dosen, Mahasiswa, dan Pegawai juga dapat membuat akun repositori personal untuk memudahkan upload data secara individu.

Pendekatan reward and punishment akan memberikan hasil optimal dalam mewajibkan seluruh dosen dalam menggunakan email, blog, dan Google Cendekia. Kegiatan-kegiatan yang bersifat sosialisasi masih kurang diminati oleh dosen. Namun jika terdapat apresiasi bagi pemeroleh nilai h-indeks, maka dosen akan berlomba-lomba dalam meningkatkan h-indeks Google Cendekia yang mereka miliki.

Selain itu, hasil penelusuran menunjukkan bahwa banyak karya ilmiah dosen telah dipublikasikan secara online. Karya tersebut pun telah dikutip banyak karya lain menurut penelusuran Google Cendekia. Hal yang sangat disayangkan adalah dosen yang karyanya dikutip belum memiliki profil dalam Google Cendekia sehingga mengakibatkan tidak terdeteksinya banyak kutipan, h-index, dan i10-index yang diperoleh dosen tersebut.

\section{Saran}

Beberapa saran yang diajukan yaitu (1) bagi pihak universitas agar terus melakukan sosialisasi pentingnya peringkat Webometrics serta pentingnya penggunaan fasilitas yang mengarahkan terciptanya pembelajaran berbasis e-learning, (2) bagi pihak universitas agar menyelenggarakan ajang award (penghargaan) insan produktif dari kalangan dosen dan/atau mahasiswa dengan menggunakan Google Cendekia sebagai instrumen penilaian. Hal tersebut diyakini menjadi motivasi untuk sivitas akademika dalam fastabiqul khairat, (3) bagi pihak fakultas agar dapat membentuk tim taskforce pembuatan profil Google Cendekia untuk seluruh dosen FITK UIN Jakarta sekaligus profil Google Cendekia untuk prodi dan fakultas sehingga dapat diketahui jumlah sitasi, h-index, dan i10-index yang diperoleh, dan (4) bagi sivitas akademika universitas agar ikut berpartisipasi aktif dalam meningkatkan peringkat Webometrics universitas. Usaha pihak universitas akan sia-sia jika tidak didukung dengan partisipasi seluruh warga kampus.

\section{DAFTAR PUSTAKA}

Chandraleka, H. (2015). Memahami h-index dan i10index dari Google Scholar. Diakses dari http:/ / ilmukomputer.org/2014/03/06/memahami-hindex-dan-i10-index-dari-google-scholar/.

Direktorat Komunikasi dan Sistem Informasi. (2010). Peningkatan rangking situs web Institut Pertanian Bogor, Bogor: Direktorat Komunikasi dan Sistem Informasi.

Jati, H. (2013). Metode baru pemeringkatan webometrics universitas dengan multicriteria decision analysis. Yogyakarta: UNY Press.

LPM UIN Jakarta. (Februari, 2015), Peringkat webometrics UIN Jakarta tertinggi di PTAIN. lpjm.uinjkt.ac.id. Diakses dari http://lpm. uinjkt.ac.id/dashboard/berita/314/PeringkatWebometrics-UIN-Jakarta-Tertinggi-di-PTAIN pada tanggal 18 April 2015.

Pedoman Akademik Program Strata I 2014/2015. (2015). Jakarta: UIN Jakarta.

Pustipanda UIN Jakarta. (Februari, 2015). Katalog layanan IT. hepdesk.uinjkt.ac.id. Diakses dari http://helpdesk.uinjkt.ac.id/8070/ pada tanggal 18 April 2015.

Pustipanda UIN Jakarta. (Februari, 2015). Produkproduk pustipanda UIN Jakarta. pustipanda. uinjkt.ac.id. Diakses dari http://pustipanda. uinjkt.ac.id/services/ pada tanggal 18 April 2015.

Redaksi UIN News. (Februari, 2015). Webometrics UIN Jakarta ranking pertama di PTAIN. uinjkt. ac.id. Diakses dari http://www.uinjkt.ac.id/ id/webometrics-uin-jakarta-ranking-pertamadi-ptain/ pada tanggal 18 April 2015.

Rusman. (2012). Pembelajaran berbasis teknologi informasi dan komunikasi. Jakarta: PT. RajaGrafindo Persada. 
Profil Google Scholar ...

Susrini, N. K. (2009). Google: Mesin pencari yang ditakuti raksasa microsoft. Yogyakarta: B First. 